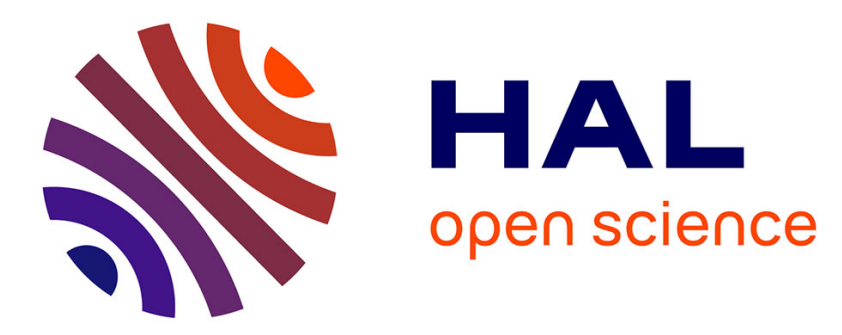

\title{
beta 2-adrenoreceptor stimulation dampens the LPS-induced M1 polarization in pig macrophages
}

Elodie Bacou, Karine Haurogne, Marie Allard, Grégoire Mignot, Jean-Marie

Bach, Julie Herve, Blandine Lieubeau-Teillet

\section{- To cite this version:}

Elodie Bacou, Karine Haurogne, Marie Allard, Grégoire Mignot, Jean-Marie Bach, et al.. beta 2adrenoreceptor stimulation dampens the LPS-induced M1 polarization in pig macrophages. Developmental and Comparative Immunology, 2017, 76, pp.169-176. 10.1016/j.dci.2017.06.007 . hal01608294

\section{HAL Id: hal-01608294 \\ https://hal.science/hal-01608294}

Submitted on 26 May 2020

HAL is a multi-disciplinary open access archive for the deposit and dissemination of scientific research documents, whether they are published or not. The documents may come from teaching and research institutions in France or abroad, or from public or private research centers.
L'archive ouverte pluridisciplinaire HAL, est destinée au dépôt et à la diffusion de documents scientifiques de niveau recherche, publiés ou non, émanant des établissements d'enseignement et de recherche français ou étrangers, des laboratoires publics ou privés.

$$
\text { Copyright }
$$




\title{
32-adrenoreceptor stimulation dampens the LPS-induced M1 polarization in pig macrophages
}

\author{
Elodie Bacou ${ }^{1}$, Karine Haurogné ${ }^{1}$, Marie Allard, Grégoire Mignot, Jean-Marie Bach, \\ Julie Hervé $^{* *}, 2$, Blandine Lieubeau ${ }^{*}, 2$ \\ IECM, INRA, Oniris, UBL, Nantes, France
}

\section{A R T I C L E I N F O}

\section{Article history:}

Received 13 April 2017

Received in revised form

16 June 2017

Accepted 16 June 2017

Available online 17 June 2017

\section{Keywords:}

Adrenoreceptor

$\beta 2$-agonist

Macrophage

Pig

\begin{abstract}
A B S T R A C T
The cross-talk between sympatho-adreno-medullar axis and innate immunity players was mainly studied in rodents. In intensive husbandry, pigs are exposed to multiple stressors inducing repeated releases of catecholamines that bind to adrenoreceptors (AR) on target cells. Among adrenoreceptors, the $\beta 2$-AR is largely expressed by immune cells including macrophages. We report herein on the effects of catecholamines, through $\beta 2$-AR stimulation, on pig macrophage functions activated by LPS.

$\beta 2$-AR stimulation of porcine macrophages prevented the LPS-induced increase in TNF $\alpha$ and IL- 8 secretion while increasing IL-10 secretion. In contrast, treatment with a $\beta 2$-agonist had no effect on anti-microbial functions. Lastly, $\beta 2$-AR stimulation of macrophages reduced the expression of genes upregulated by LPS. Altogether, we demonstrated that $\beta 2$-AR stimulation of porcine macrophages prevented polarization towards a pro-inflammatory phenotype. Since porcine macrophages are a suitable model for human macrophages, our results might be relevant to appreciate catecholamine effects on human macrophages.
\end{abstract}

() 2017 Elsevier Ltd. All rights reserved.

\section{Introduction}

Macrophages are essential for the maintenance of body homeostasis. Diverse populations of macrophages have been described with distinct roles in inflammation, tissue homeostasis and repair based on their ontogeny and the tissue microenvironment (Guilliams et al., 2014; Reynolds and Haniffa, 2015). Tissue-resident macrophages essentially arise from embryonic precursors and exhibit specialized functions (Mass et al., 2016). Monocyte-derived macrophages poorly contribute to the pool of tissue-resident macrophages in steady-state conditions and are recruited in case of inflammation. Within tissue, macrophages are exposed to multiple signals and are able to respond to various environmental stimuli.

Abbreviations: AR, adrenoreceptor; BMM, bone marrow-derived macrophages; ROS, reactive oxygen species.

* Corresponding author.

** Corresponding author.

E-mail addresses: julie.herve@oniris-nantes.fr (J. Hervé), blandine.lieubeau@ oniris-nantes.fr (B. Lieubeau).

1 These authors equally contributed to this work.

2 These authors equally contributed to this work.
In case of infection, macrophages are activated by danger signals and play a key role in innate immunity constituting an essential phagocyte population for clearance of invading pathogens. In vitro activation studies using different activators led to a classification of macrophages into two opposite populations, M1 and M2 (Mantovani et al., 2005). Classically-activated M1 macrophages secrete high amount of pro-inflammatory cytokines such as TNF $\alpha$, IL-12 and IL-23, in response to treatment by interferon $\gamma$ (IFN $\gamma$ ) and/or the lipopolysaccharide (LPS) TLR4-ligand, thereby promoting Th1 and Th17 immune responses. M1 macrophages also produce anti-microbial effectors, such as reactive oxygen species (ROS), that contribute to pathogens clearance. If alternativelyactivated macrophages were initially generated using IL-4, the M2 term is now used to describe macrophages generated with nonclassical activators and involved in Th2 immune responses, tissue repair and/or remodelling. In order to favour data comparison, Murray et al. recently proposed a unified nomenclature of macrophages based on the activator used along the culture (Murray et al., 2014).

A growing interest in porcine immunology has raised during the last decades with the opportunity to use pig as a model for human diseases and even as a donor of porcine cells/organs to treat human patients (Meurens et al., 2012; Denner, 2016). Moreover, intensive 
pig husbandry has participated to the spread of porcine infectious diseases, leading to the widespread use of antibiotics, which constitutes a public health problem. Thus, identifying factors controlling macrophage functions in vivo represents a major challenge to better understand and eventually control infectious diseases in pigs.

In intensive pig husbandry, piglets are exposed to numerous stressful events known to induce the release of catecholamines. In the course of the stress response, sympathetic nerve fibers release norepinephrine while the medullar part of the adrenal gland mainly release epinephrine into the bloodstream. These catecholamines signal through $\alpha$ - and $\beta$-adrenergic receptors (AR) and induce heart and respiratory rate increase, peripheral vasoconstriction, blood pressure elevation, and glucose release. Based on affinity studies, it is generally accepted that norepinephrine and epinephrine exhibit a higher affinity for $\alpha$ - and $\beta$-adrenoreceptors respectively (Padro and Sanders, 2014).

More recently, catecholamines were shown to modulate immune functions (reviewed in (Bellinger and Lorton, 2014). Macrophages express ARs and catecholamines display contrasted effects on their functions, depending on their origin/activation state, the available concentration of catecholamines in their surroundings and the type of AR involved. In murine models, epinephrine and norepinephrine were demonstrated to decrease LPS-induced TNF $\alpha$ secretion while increasing IL-10 production by macrophages though a $\beta 2$-AR dependent mechanism (Muthu et al., 2005; Grailer et al., 2014). In contrast, norepinephrine was shown to increase the LPS-induced TNF $\alpha$ secretion through $\alpha$-AR stimulation (Spengler et al., 1990; Huang et al., 2012). At present, $\alpha$-AR stimulation of macrophages is thought to ramp up inflammation while $\beta$-AR stimulation might inhibit inflammatory responses (Barnes et al., 2015).

Conservation of the mononuclear phagocyte organization across human, mouse and pig was recently pointed out by transcriptomic data (Manh et al., 2015). Nevertheless, swine and human macrophages poorly activated the arginine pathway enzymes following LPS stimulation in contrast with mouse macrophages which upregulated Arginase 1 and inducible nitric oxide (NO) synthase gene expression and produced NO in response to LPS; in both swine and human macrophages, LPS is rather known to activate tryptophan pathway enzymes such as indoleamine 2,3-dioxygenase 1 (IDO1) (Murray et al., 1989; Kapetanovic et al., 2012; Schroder et al., 2012; Thomas and Mattila, 2014).

Most of the studies aiming at depicting the effects of $\beta 2$ adrenergic stimulation on macrophages have been carried out in rodent models (Sigola and Zinyama, 2000; Gosain et al., 2007; Muthu et al., 2010; Tanaka et al., 2010; Grailer et al., 2014). In this context, the aim of the current study was to investigate whether catecholamines and formoterol, a specific $\beta 2$-agonist, modulate the functions of swine macrophages activated by LPS. For this purpose, we generated bone marrow-derived macrophages (BMM) as described by Kapetanovic et al. (2012). Our results indicate that BMM expressed 6 different ARs including $\beta 2$-AR. $\beta 2$-AR activation reduced LPS-induced TNF $\alpha$ and IL- 8 secretion, while increasing IL10 secretion by pig macrophages. BMM antimicrobial functions (phagocytosis, phagosome acidification and ROS production) were not altered by $\beta 2$-agonist treatment. Lastly, $\beta 2$-AR stimulation of BMM reduced LPS-induced IL7R, CXCL13, CCL20 and IDO1 gene expression.

Altogether, our data demonstrate that catecholamines dampen pro-inflammatory functions of swine macrophages through $\beta 2$-AR stimulation, which could be of major interest for translational research.

\section{Materials and methods}

\subsection{Reagents}

Epinephrine, norepinephrine, Escherichia coli 0111:B4 lipopolysaccharide (LPS) and Accutase ${ }^{\circledR}$ were purchased from SigmaAldrich (St Quentin-Fallavier, France). Formoterol ( $\beta 2$-AR agonist) and ICI-118,551 ( $\beta 2-A R$ antagonist) were obtained from Tocris Biosciences (Bristol, UK) and Pam2CSK4 originated from InvivoGen (Toulouse, France). Recombinant human Macrophage-Colony Factor (rhM-CSF) was purchased from Miltenyi-Biotec (Bergisch Gladbach, Germany) and Alexa Fluor ${ }^{\circledR} 647$ succinimidyl ester (AF647) fluorescent dye came from Thermo Fisher Scientific (Paysley, UK).

\subsection{Cell isolation and culture}

Bone marrow cells were harvested post-mortem from five to twelve day-old specific pathogen-free Large-White piglets (ANSES, Ploufragan, France), according to the French Regulations.

Bone marrow-derived macrophages (BMM) were obtained as previously described with some minor modifications (Kapetanovic et al., 2012). Briefly, both femur extremities were cut and, using a $10 \mathrm{ml}$ syringe with $18 \mathrm{G}$ needle, bone marrow cells were flushed with RPMI 1640 medium (PAA, Velizy-Villacoublay, France) containing 5 mM EDTA. Red blood cells were lysed with AmmoniumChloride-Potassium lysis buffer. Bone marrow cells were frozen in freezing medium ( $90 \%$ fetal calf serum and 10\% DMSO).

To differentiate BMM, quickly thawed bone marrow cells were cultured for 6 days at $37{ }^{\circ} \mathrm{C}$ in complete medium: RPMI 1640 with $10 \%$ fetal calf serum, $1 \%$ Penicillin/Streptomycin and $1 \%$ L-Glutamine in the presence of rhM-CSF $\left(10^{4} \mathrm{U} / \mathrm{ml}\right)$. Adherent cells were detached with Accutase ${ }^{\circledR}$ and cells were seeded in non-tissue culturetreated plates $\left(1.5 \times 10^{5}\right.$ cells $\left./ \mathrm{cm}^{2}\right)$. The next day, floating cells were removed, and adherent cells were treated with TLR ligands (10 ng/ $\mathrm{ml}$ LPS or $1 \mathrm{ng} / \mathrm{ml}$ Pam2CSK4) in the presence or not of adrenergic agonists $\left(10^{-7} \mathrm{M}\right.$ epinephrine, $10^{-7} \mathrm{M}$ norepinephrine or $10^{-9} \mathrm{M}$ formoterol) $+/-$ the $\beta 2-A R$ antagonist ICI-118,551 $\left(10^{-5} \mathrm{M}\right)$.

\subsection{Flow cytometry analysis}

After 6 days of culture, BMM were stained in the dark for 20 min at $4{ }^{\circ} \mathrm{C}$ with monoclonal mouse antibodies specific for pig proteins. FITC-conjugated anti-CD14 (MIL2 clone) and anti-SLA-DR (2E9/13 clone), PE-conjugated anti-CD16 (G7 clone) and antiCD163 (2A10/11 clone) antibodies were purchased from AbD Serotec (Kidlington, UK). FITC-conjugated mouse IgG2b and PEconjugated mouse IgG1 isotype controls came from BD Biosciences (Le Pont de Claix, France). After washing, acquisitions were performed on a FACS Aria flow cytometer (BD Biosciences) and data were analysed with FlowJo software (FlowJo version 10.1, Ashland, Oregon).

\section{4. $P C R$ and quantitative real-time $P C R(R T-q P C R)$}

Macrophages were detached and mRNAs were extracted from 3 to $3.5 \times 10^{6}$ cells using Dynabeads mRNA DIRECT kit (Thermo Fisher Scientific) and converted into cDNA using SuperScript ${ }^{\mathbb{R}}$ IV Reverse Transcriptase (Thermo Fisher Scientific).

Primer sequences were designed using Primer3Plus software (Table 1) and obtained from Eurogentec (Angers, France).

RT-PCR analyses were performed on a 9700 thermocycler (Applied Biosystems, Courtaboeuf, France) using Firepol ${ }^{\circledR}$ Master Mix (Solis BioDyne, Tartu, Estonia). cDNA samples were amplified for 35 cycles $\left[95{ }^{\circ} \mathrm{C}\right.$ for $30 \mathrm{~s}, 60{ }^{\circ} \mathrm{C}$ for $45 \mathrm{~s}$ (except for $A D R B 3$ 
Table 1

Primer sequences.

\begin{tabular}{|c|c|c|c|c|}
\hline Genes & Sequences & & Size of PCR product & GenBank accession number \\
\hline \multicolumn{5}{|c|}{ RT-PCR primers } \\
\hline \multirow[t]{2}{*}{$A D R a 1 B$} & Forward & 5'-AACCAGACCTCGAGCAACTC-3' & $90 \mathrm{bp}$ & XM_003134101 \\
\hline & Reverse & 5'-AAAGAGGATGAAGGCACCCA-3' & & \\
\hline \multirow[t]{2}{*}{ ADRa1D } & Forward & 5'-AAAGCCGCCCTACTCCTTC-3' & 170 bp & NM_001123073 \\
\hline & Reverse & $5^{\prime}$-TAAGGACACAGCCTCCACCT-3' & & \\
\hline \multirow[t]{2}{*}{$A D R a 2 A$} & Forward & 5'-AGCTGGAATGGGACAGAGG-3' & 113 bp & NM_214400 \\
\hline & Reverse & 5'-AACACGGTGAACAGCATGAG-3' & & \\
\hline \multirow[t]{2}{*}{$A D R a 2 B$} & Forward & 5'- CTGGGGAGAAGGATGAAGGG-3' & 106 bp & NM_001037148 \\
\hline & Reverse & 5'-ACACCTTCCTTCTGACCCTG-3' & & \\
\hline \multirow[t]{2}{*}{$A D R a 2 C$} & Forward & 5'-TGAGAGGTCAGAGGCACAGA-3' & $59 \mathrm{bp}$ & XM_005666516 \\
\hline & Reverse & 5'-TGGCTCCTTTCTCAССААСТ-3' & & \\
\hline \multirow{2}{*}{$A D R b 1$} & Forward & 5'-AGCCCTGCAACCTGTCATC-3' & 125 bp & NM_001123074 \\
\hline & Reverse & $5^{\prime}$-CAGCTGCACGGATCCCTC-3' & & \\
\hline \multirow[t]{2}{*}{$A D R b 2$} & Forward & 5'-GAGGAGAAAGACAGCGAACG-3' & 147 bp & NM_001128436 \\
\hline & Reverse & 5'-ATCATCGGGCACAGTACCTT-3' & & \\
\hline \multirow[t]{2}{*}{ ADRb3 } & Forward & 5'-GCTCATCATGGGAACCTTCACTCT-3' & 119 bp & NM_001099927 \\
\hline & Reverse & 5'-CTAGCCAGTTAAGGGCGAGGAAAG-3' & & \\
\hline \multicolumn{5}{|c|}{ RT-qPCR primers } \\
\hline \multirow[t]{2}{*}{ IRF5 } & Forward & 5'-TACGAGGTCTGCTCCAATGG-3' & $68 \mathrm{bp}$ & XM_003134683 \\
\hline & Reverse & 5'-GGCCCGAGACAGTAATCCTC-3' & & \\
\hline \multirow[t]{2}{*}{ IRF4 } & Forward & 5'-GGGACAGGAACCTTTTATG-3' & 212 bp & NM_001253352 \\
\hline & Reverse & 5'-TGCTGGCATCGTAGGTGTG-3' & & \\
\hline \multirow[t]{2}{*}{ MMP9 } & Forward & 5'-TTATGGCTTCTGCCCTACCC-3' & 216 bp & NM_001038004 \\
\hline & Reverse & 5'-AGGAACAGGCTGTAGCCTTG & & \\
\hline \multirow[t]{2}{*}{ IDO1 } & Forward & 5'-GGCACTTGATTGGTGGTCTC-3' & 123 bp & NM_001246240 \\
\hline & Reverse & 5'-GCAATCCAAGCATCGTAAGG-3' & & \\
\hline \multirow[t]{2}{*}{ CXCL13 } & Forward & 5'-GGATCTCTGCTTCTCGTGCT-3' & $122 \mathrm{bp}$ & XM_003129101 \\
\hline & Reverse & 5'-ATAGGGACCCAGTTCGAGGT-3' & & \\
\hline \multirow[t]{2}{*}{ CCL20 } & Forward & 5'-GCTCCTGGCTGCTTTGATGTC-3' & 146 bp & NM_001024589 \\
\hline & Reverse & 5'-CATTGGCGAGCTGCTGTGTG-3' & & \\
\hline \multirow[t]{2}{*}{ CD206 } & Forward & 5'-CCACAGTTACCCCCACCATA-3' & 165 bp & NM_001255969 \\
\hline & Reverse & 5'-TAGACGCCAGATTTCCTCCA-3' & & \\
\hline \multirow[t]{2}{*}{ IL7R } & Forward & 5'-CATTCTGGCCTGTGTGTTGTG-3' & $64 \mathrm{bp}$ & NM_001146128 \\
\hline & Reverse & 5'-ATCTGGGAGACTGGGCCATA-3' & & \\
\hline \multirow[t]{2}{*}{ PPARg } & Forward & $5^{\prime}-$ CCATTCCCGAGAGCTGATCC-3' & $93 \mathrm{bp}$ & NM_214379 \\
\hline & Reverse & 5'-GGACACAGGCTCCACTTTGA-3' & & \\
\hline \multicolumn{5}{|c|}{ Housekeeping gene primers } \\
\hline \multirow[t]{2}{*}{ Actin } & Forward & 5'-ATCAAGATCATCGCGCCTCC-3' & $160 \mathrm{bp}$ & XM_003357928 \\
\hline & Reverse & 5'-CGCAGTCCGTCTAGAAGCAT-3' & & \\
\hline \multirow[t]{2}{*}{ RPL19 } & Forward & 5'-AACTCCCGTCAGCAGATCC-3' & 147 bp & NM_001206359 \\
\hline & Reverse & 5'-AGTACCCTTCCGCTTACCG-3' & & \\
\hline
\end{tabular}

hybridation temperature at $63{ }^{\circ} \mathrm{C}$ ) and $72{ }^{\circ} \mathrm{C}$ for $45 \mathrm{~s}$ ] and PCR products were run on $2 \%$ agarose gel. Actin gene expression was used as positive control.

RT-qPCR were performed on an ABI Prism 7300 Sequence Detection instrument (Applied Biosystems) using EvaGreen ${ }^{\circledR}$ dye (Solis BioDyne). All cDNA samples were run in duplicate in 96-well optical reaction plates. In each run, control cDNA dilution series were created for each primer pair to establish relative standard curves. Melting curve analysis was performed $\left(65^{\circ} \mathrm{C}-95^{\circ} \mathrm{C}\right)$ in order to confirm the presence of unique amplified products. Data were analysed with the relative quantification standard curve method; Actin and RPL19 were chosen as housekeeping genes (Facci et al., 2011) and target gene expression was normalized using GeNorm matrix.

\subsection{Cytokine assay}

After $24 \mathrm{~h}$ of treatment, supernatants were collected, centrifuged and stored at $-80^{\circ} \mathrm{C}$. Porcine TNF $\alpha$, IL- 10 and IL- 8 cytokine concentrations were determined using ELISA according to manufacturer's instructions (Bio-Techne, Abingdon, UK).

\subsection{Bacteria labelling}

Escherichia coli ATCC $^{\circledR} 25,922^{\mathrm{TM}}$, kind gift from M. Zagorec,
SECALIM) were cultured in Luria-Bertani broth until midexponential growth phase was reached. Bacteria were centrifuged and heat-inactivated at $65{ }^{\circ} \mathrm{C}$ for $30 \mathrm{~min}$. Then, bacteria $\left(10^{9} / \mathrm{ml}\right)$

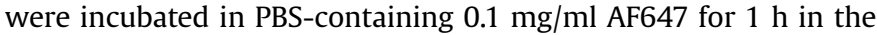
dark at room temperature with continuous shaking. The labelling was stopped by adding PBS $1 \%$ BSA. Then, bacteria were opsonized by re-suspension and incubation in PBS containing $50 \%$ of inactivated porcine serum for $30 \mathrm{~min}$ at $37{ }^{\circ} \mathrm{C}$. Labelled bacteria were washed with PBS and stored in PBS at $4{ }^{\circ} \mathrm{C}$.

\subsection{Phagocytosis assay}

After $18 \mathrm{~h}$ of treatment, BMM were detached with Accutase ${ }^{\circledR}$ and incubated with AF647-labelled E. coli bacteria at a 1 to 4 ratio for $20 \mathrm{~min}$ at $37^{\circ} \mathrm{C}$. Then, BMM were washed twice with ice-cold PBS containing $5 \mathrm{mM}$ EDTA and immediately analysed using flow cytometry. For each experiment, samples incubated on ice were used as negative controls.

\subsection{Reactive oxygen species (ROS) measurement}

For these analyses, $5 \times 10^{4}$ BMM were seeded and treated in white clear-bottomed 96-well plates (Dutscher, Brumath, France). Eighteen hours later, the ability of macrophages to produce ROS was assessed by chemiluminescence after incubation in medium 
containing Horseradish peroxidase ( $8 \mathrm{U} / \mathrm{ml}$, Sigma-Aldrich) and luminol (50 $\mu \mathrm{M}$, Sigma-Aldrich) as described (Dahlgren et al., 2007). Triggering of the respiratory burst was induced by Phorbol 12-myristate 13-acetate (PMA, $0.2 \mu \mathrm{M}$, Sigma-Aldrich). Luminescence, expressed as relative light units (RLU), was recorded immediately and every 2 min for 120 min by using the Fluostar luminometer (BMG LABTECH, Champigny s/Marne, France). For each condition, spontaneous luminescence was recorded (in the absence of PMA) in paired wells, which allowed quantification of specific PMA-induced ROS by measurement of the area under curve (AUC).

\subsection{Statistical analysis}

Graphs and statistical analyses were performed using GraphPad Prism version 6.0 (GraphPad Software, La Jolla, CA). On charts, each symbol represents mean of replicate wells from one pig sample, while lines denote medians. Results of at least four independent experiments performed with cells from four different donors are shown. All statistical analyses were performed using nonparametric paired tests (for repeated measures). Friedman's test was used to compare three groups of identical size followed by Dunn's post-tests. Otherwise, the Wilcoxon signed rank test was used to assess the effect of the $\beta 2$-adrenergic agonist. Significance level was set up at $\mathrm{p}<0.05$ (with ${ }^{*} \mathrm{p}<0.05 ;{ }^{* *} \mathrm{p}<0.01$ on charts).

\section{Results}

\subsection{Characterization of porcine BMM}

After 6 days of culture in the presence of rhM-CSF, the majority of cells were adherent cells displaying typical macrophage morphology with numerous vacuoles. After enzymatic detachment of BMM, their phenotype was assessed by flow cytometry (Fig. 1). The majority of cells ( $\approx 70 \%$ of the total cell population) exhibited high cell size and granularity (FSC ${ }^{\text {hi }}$ SSC $^{\text {hi }}$ ). These FSC $^{\text {hi }}$ SSC ${ }^{\text {hi }}$ cells expressed CD14 (a LPS co-receptor), CD16 (a low affinity receptor for IgG Fc), CD163 (a macrophage scavenger receptor) and SLA-DR (class II swine leucocyte antigens), showing that these cells were macrophages.

\subsection{Adrenergic receptor $m R N A$ expression in BMM}

In pigs, as well as in other mammals, nine $A D R$ genes encoding different ARs have been described: three $\alpha 1$ isoforms ( $\alpha 1 \mathrm{~A}, \alpha 1 \mathrm{~B}$ and $\alpha 1 D)$, three $\alpha 2$ isoforms ( $\alpha 2 \mathrm{~A}, \alpha 2 \mathrm{~B}$ and $\alpha 2 \mathrm{C})$ and three $\beta$ genes ( $\beta 1$, $\beta 2$ and $\beta 3$ ).

We performed RT-PCR analyses for the expression of all AR genes. For the $A D R \alpha 1 A$ isoform, the amplicon did not exhibit the expected size for macrophages, although we validated the primers on lung tissue. Related data were thus discarded.

As shown in Fig. 2, BMM expressed six different ARs: two $\alpha 1$ isoforms ( $\alpha 1 B$ and $\alpha 1 D$ ), two $\alpha 2$-isoforms ( $\alpha 2 A$ and $\alpha 2 B$ ) as well as

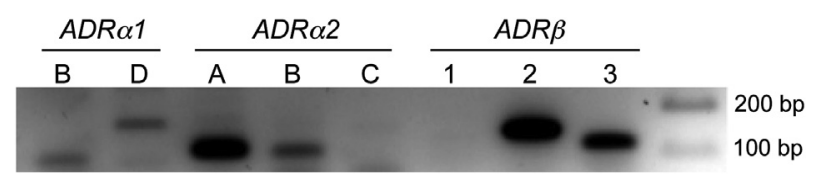

Fig. 2. Adrenoreceptor mRNA expression in porcine BMM.

AR expression in BMM (after day 6 of culture) was determined by RT-PCR analyses. Primer pair sequences and PCR product sizes are listed in Table 1. One electrophoresis representative of 3 independent experiments is shown.

$\beta 2$-and $\beta 3-A R$. The expression of the $\beta 2$-adrenoreceptor allowed us to explore catecholamine and formoterol effects on porcine macrophages.

\section{3. $\beta 2-A R$ stimulation effect on cytokine secretion by BMM}

We first analysed the effects of catecholamines on LPS-induced cytokine secretion in BMM.

In the absence of LPS, TNF $\alpha$ and IL-10 were not detectable while unstimulated BMM produced IL-8 (range: $0.1-7.8 \mathrm{ng} / \mathrm{ml}, \mathrm{n}=6$ ). LPS induced the secretion of high amount of IL-8 together with moderate TNF $\alpha$ and IL-10 release (Fig. 3).

In the following experiments, both epinephrine and norepinephrine were used at the same $10^{-7} \mathrm{M}$ concentration, which was found to inhibit TNF $\alpha$ secretion in beforehand dose-response experiments (Suppl. Fig. 1). Epinephrine impaired the LPS-induced TNF $\alpha$ secretion $(\mathrm{p}<0.01$ ) and, slightly but not significantly, the LPS-induced IL- 8 one while $\beta 2$-AR blockade by ICI-118,551 antagonist reverted its effects. Norepinephrine also lowered TNF $\alpha$ production in four out of six pig samples. In contrast, catecholamines did not modulate IL-10 production.

When using a TLR2/6 ligand (Pam2CSK4), we obtained comparable results (Suppl. Fig. 2). Epinephrine prevented Pam2CSK4induced TNF $\alpha$ and IL-8 secretions while norepinephrine had low or no effect. Catecholamines did not affect Pam2CSK4-induced IL10 release.

To confirm the involvement of the $\beta 2$-AR in the regulation of cytokine secretion, we next investigated the ability of the selective $\beta 2-A R$ agonist formoterol to modulate cytokine secretion following LPS stimulation of BMM.

Such as catecholamines did, formoterol also lowered LPSinduced TNF $\alpha$ and IL-8 secretion (Fig. 4). Interestingly, it also significantly increased IL-10 secretion. Addition of ICI-118,551 abolished the effects of formoterol thereby confirming the $\beta 2$ adrenoreceptor involvement in the modulation of macrophage function.

\subsection{Formoterol effects on BMM antimicrobial functions}

Next, we analysed the effects of formoterol on the ability of BMM to phagocyte fluorescent $E$. coli bacteria. While LPS-treated BMM efficiently phagocytosed bacteria (35\%), neither a 3-h

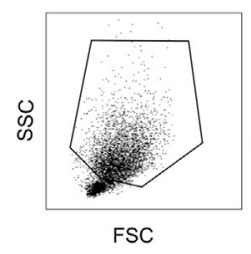

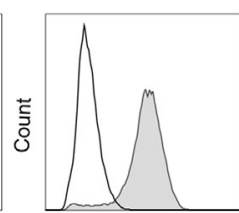

CD14

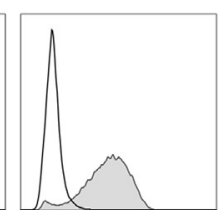

CD16

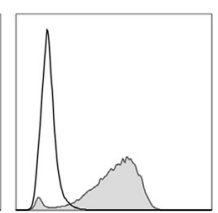

CD163

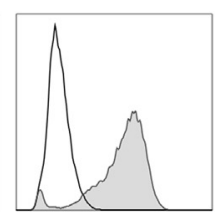

SLA-DR

Fig. 1. Phenotype of porcine BMM.

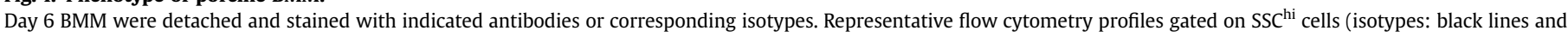
specific antibodies: filled grey curves). 

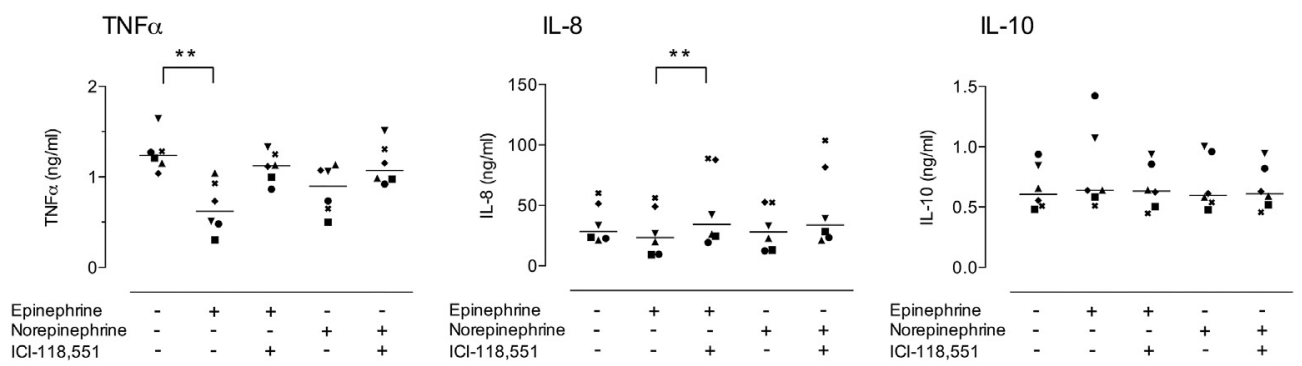

Fig. 3. Effect of catecholamines on LPS-induced TNF $\alpha$, IL-8 and IL-10 secretion by porcine BMM.

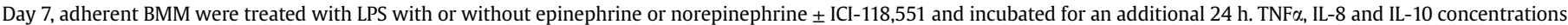
in the supernatants were evaluated by ELISA. Data from 6 different animals, in 6 independent experiments, are shown.
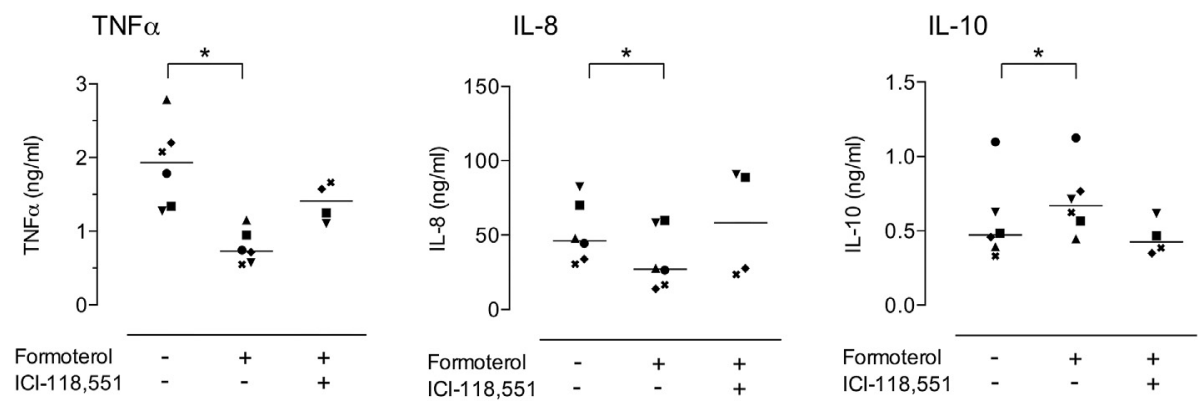

Fig. 4. $\beta 2-A R$ dependent effect of formoterol on LPS-induced TNF $\alpha$, IL-8 and IL-10 secretion by porcine BMM.

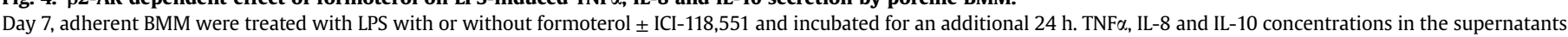
were evaluated by ELISA. Data from 6 different animals, in 6 independent experiments, are shown except for the effect of ICI-118,551, which was tested in 4 experiments.

treatment (data not shown) nor an 18-h treatment with formoterol had any effect on the percentage of phagocytosing macrophage (Fig. 5). Moreover, the mean fluorescence intensity of macrophages that have ingested bacteria, which represents a measure of the phagocytosis index, was not modulated by formoterol treatment (data not shown).

We also measured phagosomal $\mathrm{pH}$ following a 15-min incubation of porcine BMM with FITC- and AF647- co-labelled bacteria. While LPS-stimulated BMM displayed efficient phagosomal acidification following phagocytosis, formoterol did not affect this process (Suppl. Fig. 3).

Then, we assessed ROS production by BMM using the luminol-

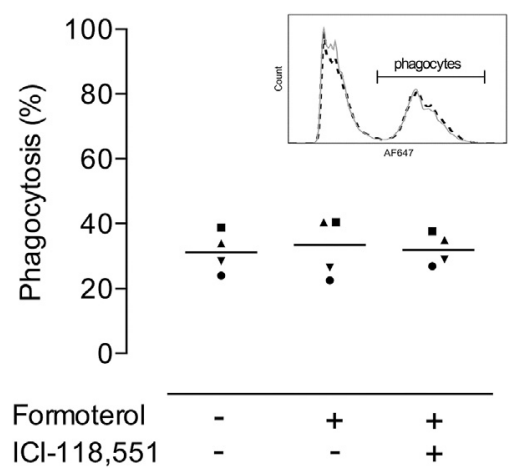

Fig. 5. Effect of formoterol on phagocytosis by LPS-treated porcine BMM

Day 7, adherent BMM were treated with LPS with or without formoterol \pm ICI-118,551. After $18 \mathrm{~h}$, cells were detached and incubated with fluorescent $E$. coli bacteria. Phagocytosis was evaluated after $20 \mathrm{~min}$ of incubation by flow cytometry in duplicate samples. Percentage of BMM that have ingested bacteria are shown. Data from 4 different animals, in 4 independent experiments, are shown. Inset, representative flow cytometry profiles: LPS- (grey line) and LPS and formoterol-treated BMM (black dashed line). dependent chemiluminescence assay. A representative profile is shown in Fig. 6A. Following PMA induction, LPS-treated BMM produced systematically more ROS than untreated cells; formoterol did not change ROS release (Fig. 6B).

\section{5. $\beta 2$-agonist effect on gene expression in LPS-treated BMM}

We focused on 9 genes previously shown to be differentially expressed in human macrophages depending on their polarization: IL7R, CCL20, CXCL13, IDO1, IRF5, IRF4, CD206, MMP9 and PPAR $\gamma$. mRNA levels were quantified by RT-qPCR. In untreated BMM, all cited transcripts were detected.

LPS treatment did not affect IRF5, MMP9, IRF4, CD206 and PPAR $\gamma$ gene expression in BMM (data not shown), neither did formoterol in LPS-treated BMM (Suppl. Fig. 4).

In contrast, a 6-h LPS treatment induced a strong up-regulation of IL7R, CCL20, CXCL13 and IDO1 gene expression as expected (data not shown). Interestingly, formoterol limited the LPS-induced up-
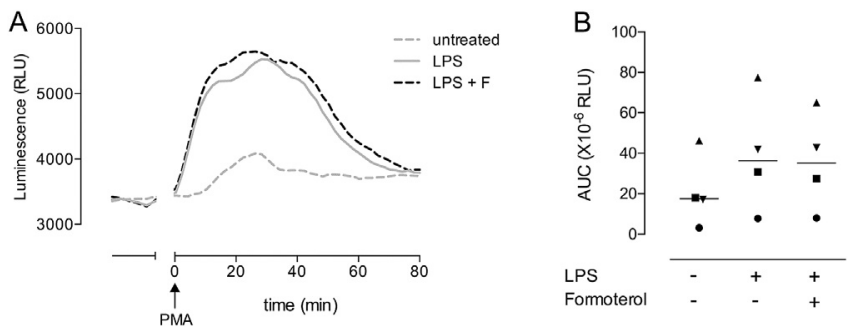

Fig. 6. Effect of formoterol on PMA-induced ROS production.

Day 7, adherent BMM were treated with LPS \pm formoterol $(F)$. After $18 \mathrm{~h}$, cells were washed, then luminol and HRP were added. Luminescence was recorded during $10 \mathrm{~min}$ before the addition of PMA. A, Example of kinetic plots. B, ROS production estimated by the AUC. Data from 4 different animals, in 4 independent experiments, are shown. 

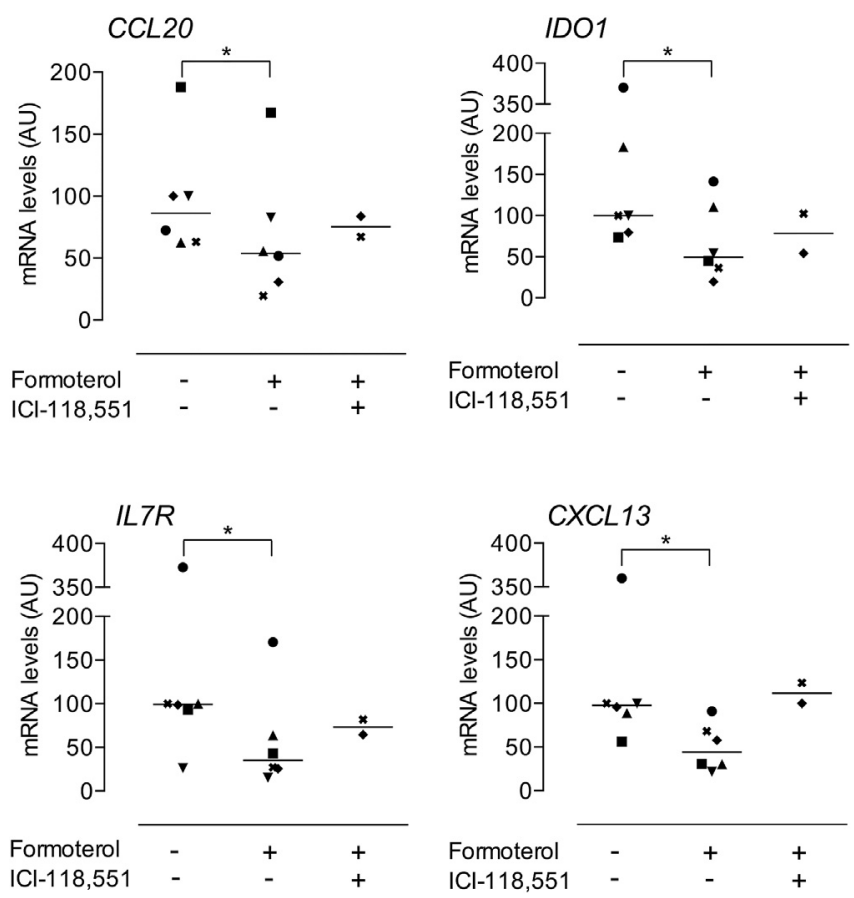

Fig. 7. $\beta 2$-AR mediated down-regulation of CCL20, IDO1, IL-7R and CXCL13 mRNA levels.

Day 7, adherent BMM were treated with LPS with or without formoterol \pm ICI-118,551 After $6 \mathrm{~h}$, cells were detached to extract mRNAs. Gene expression was quantified by RTqPCR. For each gene, data from 6 different animals in 2 independent experiments are shown, except the effect of ICl-118,551 which was tested on 2 animals in a single experiment.

regulation of IL7R, CCL20, CXCL13 and IDO1 gene expression (Fig. 7). This effect was abrogated when adding the $\beta 2$-antagonist ICI118,551 , confirming the $\beta 2$-adrenoreceptor involvement. The inhibitory effect of formoterol on gene expression was also observed when BMM were treated for 18 h (Suppl. Fig. 5).

\section{Discussion}

During the stress response, catecholamines released by both the adrenal gland and sympathetic nerve fibers regulate activity and function of immune cells. The fine-tuning of immunity by catecholamines is critical to the maintenance of homeostasis (reviewed in Madden, 2017). We report herein on the effect of catecholamines on porcine bone marrow-derived macrophage functions.

In our study, pig macrophages displayed clear expression of CD14, CD16, SLA-DR and CD163 markers. If CD14 and CD16 were previously described as monocyte/macrophage markers in swine, they are also expressed by other myeloid cells such as granulocytes (Ezquerra et al., 2009). In contrast, in pig, CD163 expression is restricted to monocytes and macrophages: to date, lung alveolar and parenchyma macrophages as well as a subset of splenic macrophages and subcapsular sinus macrophages of lymph nodes exhibit CD163 expression (Alvarez et al., 2014; Maisonnasse et al., 2016).

In view of the absence of antibodies raised against pig adrenergic receptors and the difficulty to get isoform-specific G-proteincoupled receptor antibodies (Michel et al., 2009), we did not explore protein expression of ARs in swine macrophages. We analysed their transcripts by RT-PCR and reported, for the first time, the expression of six ARs in pig macrophages: two $\alpha 1$ isoforms (ADR $\alpha 1 B$ and ADR $\alpha 1 D$ ), two $\alpha 2$ isoforms (ADR $\alpha 2 A$ and ADR $\alpha 2 B$ ), $\beta 2$-and $\beta 3$-AR. This is in agreement with previous studies indicating the presence of $\alpha 2$-and $\beta 2$-ARs on rodent and human macrophages using radio-ligand binding assay (Liggett, 1989; Spengler et al., 1990). Interestingly, the human monocytic THP1 cell line was shown to express $\alpha 1 \mathrm{~B}$ and $\alpha 1 \mathrm{D}-\mathrm{AR}$ mRNAs and, later on, to exhibit $\beta 1$-and $\beta 2$-ARs protein expression but not the $\beta 3$ one using immunoblot and radio-ligand binding assay (Heijnen et al., 2002; Grisanti et al., 2010). Thus, our results are consistent with AR expression pattern in other species, except $\beta 1$-AR mRNA that we did not detect. In addition, we identified $\beta 3-A R$ mRNA on pig macrophages. Since transcript and protein levels do not necessarily correlate, further investigations are needed to elucidate whether $\beta 3-A R$ is relevant for macrophage biology.

In rodent macrophages, previous studies have reported reduction of LPS-induced TNF $\alpha$ release by catecholamines (Sigola and Zinyama, 2000; Muthu et al., 2005; Grailer et al., 2014). In this study, we evidenced similar effect of catecholamines and $\beta 2$ agonist on porcine BMM, as previously demonstrated on porcine alveolar and liver macrophages (Izeboud et al., 2000). Our data using $\beta 2$-agonist are also in agreement with data obtained on human macrophages, except for IL-8 that was found unchanged by Donnelly et al. (Donnelly et al., 2010; Gill et al., 2016). Concordantly, we recently reported an impaired secretion of IL- 8 and TNF $\alpha$ by porcine LPS-stimulated leukocytes in whole blood assay following acute stress that we attributed to catecholamine burst (Bacou et al., 2017). We also measured decreased TNF $\alpha$ and IL- 8 secretions after epinephrine treatment of TLR2/6 ligand-stimulated BMM. These data argue for a wide anti-inflammatory effect of catecholamines on porcine macrophages.

In agreement with previous data, we found that BMM displayed anti-microbial functions such as phagocytosis of bacteria, phagosome acidification and ROS production (Chaudhuri et al., 2016). In rodents, catecholamines were previously shown to increase the phagocytic capacity of macrophages (Baccan et al., 2010; Xiu et al., 2013; Grailer et al., 2014), which was suggested to rely upon $\beta 2$-AR stimulation (Muthu et al., 2010). However, in our experimental conditions, neither formoterol nor catecholamine (data not shown) addition on LPS-stimulated porcine macrophages modulate their phagocytic capacity.

We did not evidence any effect of the $\beta 2$-agonist formoterol on ROS production by porcine macrophages, which is consistent with published data. Indeed, in human macrophages, norepinephrine treatment was shown to reduce ROS release through stimulation of $\alpha$-adrenoreceptors (Kuebler et al., 2013), as previously demonstrated in rat (Dimitrijevic et al., 2009). Of note, we did not detect any effect of catecholamine on ROS production by pig macrophages at the $10^{-7} \mathrm{M}$ concentration we used (data not shown). Whether different doses of catecholamines could modulate ROS production by porcine macrophages through $\alpha$-adrenoreceptor stimulation still needs to be addressed in a more relevant model of ROS generation, for example after infection by Salmonella typhimurium or Porcine Reproductive and Respiratory Syndrome Virus (Boyen et al., 2006; Kavanova et al., 2015).

Macrophages have the ability to respond efficiently to environmental signals by assuming distinct functional phenotypes, resulting in a wide spectrum of macrophage subtypes. To evaluate whether $\beta 2$-agonist treatment of LPS-stimulated BMM change their polarity, we quantified the expression of a set of genes previously associated to M1 or M2 phenotype (Murray et al., 2014). Among M1 genes, we analysed IL7R, CCL20, CXCL13 and IDO1 genes that were already described in porcine LPS-activated macrophages (Kapetanovic et al., 2012). $\beta 2$-agonist stimulation of pig macrophages inhibited by approximately $50 \%$ the LPS-induced expression of IL7R, CCL20, CXCL13 and IDO1 genes. It may be mentioned that formoterol effect on M1 gene expression was also observable after an 18-h treatment. Additional experiments could be performed to 
address the functional consequences of the reduced expression of these M1 genes such as analysing IDO1 activity by measuring tryptophan and kynurenine (Wirthgen et al., 2014), or assessing macrophage chemotaxis in response to IL-7 (Chen et al., 2013). Both IRF5 and MMP9 genes, suggested as M1 polarization markers in humans, were neither induced by LPS treatment nor modified by formoterol addition in porcine macrophages. These data are in agreement with studies conducted on M-CSF-differentiated human macrophages, demonstrating that LPS \pm IFN $\gamma$ did not modify IRF5 and MMP9 transcript expression (Jaguin et al., 2013; Sudan et al., 2015; Spiller et al., 2016). As expected, IRF4, CD206 and PPAR $\gamma$, which were selected among M2 genes, were not induced by LPS in porcine macrophages. Formoterol addition did not change expression of these genes. If treatment of pig BMM with a $\beta 2$ agonist efficiently prevented M1 gene expression induction, it failed to stimulate M2 gene expression in inflammatory conditions. Interestingly, a $\beta 2$-adrenoreceptor-mediated induction of M2 transcripts was recently reported in murine macrophages but in the absence of LPS stimulation (Lamkin et al., 2016).

Altogether our data demonstrate that $\beta 2$-adrenergic stimulation of pig macrophages prevented polarization towards a proinflammatory phenotype, which consolidates previous data obtained in rodent models. However, while $\beta 2$-agonist treatment of LPS-stimulated macrophages also induced an increase in IL-10 production in pig, we did not identify other M2 hallmarks, in contrast with data obtained in mouse (Grailer et al., 2014). Since porcine macrophages are considered as a suitable model for human macrophages, our results might be relevant to appreciate catecholamine effects on human macrophages. Furthermore, our description of a $\beta 2$-AR mediated anti-inflammatory effect of catecholamines provides new insights to better understand the complex relationships between stress and susceptibility to infections in pigs. As a consequence, we suggest that, in pig husbandry, reducing stress exposure by promoting animal welfare could help decrease infectious disease prevalence and antibiotic use.

\section{Funding}

This research did not receive any specific grant from funding agencies in the public, commercial, or not-for-profit sectors.

\section{Author contributions}

$\mathrm{EB}, \mathrm{KH}, \mathrm{JH}$ and $\mathrm{BL}$ conceived and designed the experiments. EB, $\mathrm{KH}$ and MA performed the experiments. EB, KH, MA, GM, JH and BL analysed and interpreted the results. $\mathrm{EB}, \mathrm{KH}, \mathrm{JMB}, \mathrm{JH}$ and $\mathrm{BL}$ wrote the manuscript. All authors read, commented on and approved the final version of the manuscript.

\section{Competing interests}

The authors declare no conflicts of interest.

\section{Acknowledgements}

The authors are grateful to Monique Zagorec (SECALIM, INRA, Oniris, UMR1014) for the kind gift and her assistance with the processing of E. coli bacteria. The biomolecular platform (PFBM, Oniris, France) provided facilities for RT-qPCR.

\section{Appendix A. Supplementary data}

Supplementary data related to this article can be found at http:// dx.doi.org/10.1016/j.dci.2017.06.007.

\section{References}

Alvarez, B., Martinez, P., Yuste, M., Poderoso, T., Alonso, F., Dominguez, J., Ezquerra, A., Revilla, C., 2014. Phenotypic and functional heterogeneity of CD169(+) and CD163(+) macrophages from porcine lymph nodes and spleen. Dev. Comp. Immunol. 44, 44-49.

Baccan, G.C., Sesti-Costa, R., Chedraoui-Silva, S., Mantovani, B., 2010. Effects of cold stress, corticosterone and catecholamines on phagocytosis in mice: differences between resting and activated macrophages. Neuroimmunomodulation 17, 379-385.

Bacou, E., Haurogne, K., Mignot, G., Allard, M., De Beaurepaire, L., Marchand, J., Terenina, E., Billon, Y., Jacques, J., Bach, J.M., Mormede, P., Herve, J., Lieubeau, B., 2017. Acute social stress-induced immunomodulation in pigs high and low responders to ACTH. Physiology Behav. 169, 1-8.

Barnes, M.A., Carson, M.J., Nair, M.G., 2015. Non-traditional cytokines: how catecholamines and adipokines influence macrophages in immunity, metabolism and the central nervous system. Cytokine 72, 210-219.

Bellinger, D.L., Lorton, D., 2014. Autonomic regulation of cellular immune function. Aut. Neuroscience-Basic Clin. 182, 15-41.

Boyen, F., Pasmans, F., Donne, E., Van Immerseel, F., Adriaensen, C., Hernalsteens, J.P., Ducatelle, R., Haesebrouck, F., 2006. Role of SPI-1 in the interactions of Salmonella Typhimurium with porcine macrophages. Veterinary Microbiol. 113, 35-44.

Chaudhuri, S., McKenna, N., Balce, D.R., Yates, R.M., 2016. Infection of porcine bone marrow-derived macrophages by porcine respiratory and reproductive syndrome virus impairs phagosomal maturation. J. General Virology 97, 669-679.

Chen, Z., Kim, S.J., Chamberlain, N.D., Pickens, S.R., Volin, M.V., Volkov, S., Arami, S., Christman, J.W., Prabhakar, B.S., Swedler, W., Mehta, A., Sweiss, N., Shahrara, S., 2013. The novel role of IL-7 ligation to IL-7 receptor in myeloid cells of rheumatoid arthritis and collagen-induced arthritis. J. Immunol. 190, 5256-5266.

Dahlgren, C., Karlsson, A., Bylund, J., 2007. Measurement of respiratory burst products generated by professional phagocytes. Methods Mol. Biol. 412, 349-363.

Denner, J., 2016. Recent progress in xenotransplantation, with emphasis on virological safety. Ann. Transplant. 21, 717-727.

Dimitrijevic, M., Pilipovic, I., Stanojevic, S., Mitic, K., Radojevic, K., Pesic, V., Leposavic, G., 2009. Chronic propranolol treatment affects expression of adrenoceptors on peritoneal macrophages and their ability to produce hydrogen peroxide and nitric oxide. J. Neuroimmunol. 211, 56-65.

Donnelly, L.E., Tudhope, S.J., Fenwick, P.S., Barnes, P.J., 2010. Effects of formoterol and salmeterol on cytokine release from monocyte-derived macrophages. Eur. Respir. J. 36, 178-186.

Ezquerra, A., Revilla, C., Alvarez, B., Perez, C., Alonso, F., Dominguez, J., 2009. Porcine myelomonocytic markers and cell populations. Dev. Comp. Immunol. 33, 284-298.

Facci, M.R., Auray, G., Meurens, F., Buchanan, R., van Kessel, J., Gerdts, V., 2011 Stability of expression of reference genes in porcine peripheral blood mononuclear and dendritic cells. Veterinary Immunol. Immunopathol. 141, 11-15.

Gill, S.K., Marriott, H.M., Suvarna, S.K., Peachell, P.T., 2016. Evaluation of the antiinflammatory effects of beta-adrenoceptor agonists on human lung macrophages. Eur. J. Pharmacol. 793, 49-55.

Gosain, A., Muthu, K., Gamelli, R.L., DiPietro, L.A., 2007. Norepinephrine suppresses wound macrophage phagocytic efficiency through alpha- and betaadrenoreceptor dependent pathways. Surgery 142, 170-179.

Grailer, J.J., Haggadone, M.D., Sarma, J.V., Zetoune, F.S., Ward, P.A., 2014. Induction of M2 regulatory macrophages through the beta(2)-adrenergic receptor with protection during endotoxemia and acute lung injury. J. Innate Immun. 6, 607-618.

Grisanti, L.A., Evanson, J., Marchus, E., Jorissen, H., Woster, A.P., DeKrey, W., Sauter, E.R., Combs, C.K., Porter, J.E., 2010. Pro-inflammatory responses in human monocytes are beta(1)-adrenergic receptor subtype dependent. Mol. Immunol. 47, 1244-1254.

Guilliams, M., Ginhoux, F., Jakubzick, C., Naik, S.H., Onai, N., Schraml, B.U., Segura, E., Tussiwand, R., Yona, S., 2014. Dendritic cells, monocytes and macrophages: a unified nomenclature based on ontogeny. Nat. Rev. Immunol. 14, 571-578.

Heijnen, C.J., van der Voort, C.R., van de Pol, M., Kavelaars, A., 2002. Cytokines regulate alpha(1)-adrenergic receptor mRNA expression in human monocytic cells and endothelial cells. J. Neuroimmunol. 125, 66-72.

Huang, J.L., Zhang, Y.L., Wang, C.C., Zhou, J.R., Ma, Q., Wang, X., Shen, X.H., Jiang, C.L., 2012. Enhanced phosphorylation of MAPKs by ne promotes TNF-alpha production by macrophage through alpha adrenergic receptor. Inflammation 35, 527-534.

Izeboud, C.A., Monshouwer, M., Witkamp, R.F., van Miert, A., 2000. Suppression of the acute inflammatory response of porcine alveolar- and liver macrophages. Veterinary Q. 22, 26-30.

Jaguin, M., Houlbert, N., Fardel, O., Lecureur, V., 2013. Polarization profiles of human M-CSF-generated macrophages and comparison of M1-markers in classically activated macrophages from GM-CSF and M-CSF origin. Cell. Immunol. 281, $51-61$.

Kapetanovic, R., Fairbairn, L., Beraldi, D., Sester, D.P., Archibald, A.L., Tuggle, C.K., Hume, D.A. 2012. Pig bone marrow-derived macrophages resemble human macrophages in their response to bacterial lipopolysaccharide. J. Immunol. 188, 3382-3394.

Kavanova, L., Prodelalova, J., Nedbalcova, K., Matiasovic, J., Volf, J., Faldyna, M., 
Salat, J., 2015. Immune response of porcine alveolar macrophages to a concurrent infection with porcine reproductive and respiratory syndrome virus and Haemophilus parasuis in vitro. Veterinary Microbiol. 180, 28-35.

Kuebler, U., Wirtz, P.H., Sakai, M., Stemmer, A., Ehlert, U., 2013. Acute stress reduces wound-induced activation of microbicidal potential of ex vivo isolated human monocyte-derived macrophages. PLoS One 8.

Lamkin, D.M., Ho, H.Y., Ong, T.H., Kawanishi, C.K., Stoffers, V.L., Ahlawat, N., Ma, J.C.Y., Arevalo, J.M.G., Cole, S.W., Sloan, E.K., 2016. beta-Adrenergic-stimulated macrophages: comprehensive localization in the M1-M2 spectrum. Brain Behav. Immun. 57, 338-346.

Liggett, S.B., 1989. Identification and characterization of a homogeneous population of beta-2 adrenergic receptors on human alveolar macrophages. Am. Rev. Respir. Dis. 139, 552-555.

Madden, K.S., 2017. Sympathetic neural-immune interactions regulate hematopoiesis, thermoregulation and inflammation in mammals. Dev. Comp. Immunol. 66, 92-97.

Maisonnasse, P., Bouguyon, E., Piton, G., Ezquerra, A., Urien, C., Deloizy, C., Bourge, M., Leplat, J.J., Simon, G., Chevalier, C., Vincent-Naulleau, S., Crisci, E., Montoya, M., Schwartz-Cornil, I., Bertho, N., 2016. The respiratory DC/macrophage network at steady-state and upon influenza infection in the swine biomedical model. Mucosal Immunol. 9, 835-849.

Manh, T.P.V., Elhmouzi-Younes, J., Urien, C., Ruscanu, S., Jouneau, L., Bourge, M., Moroldo, M., Foucras, G., Salmon, H., Marty, H., Quere, P., Bertho, N., Boudinot, P., Dalod, M., Schwartz-Cornil, I., 2015. Defining mononuclear phagocyte subset homology across several distant warm-blooded vertebrates through comparative transcriptomics. Front. Immunol. 6, 1-26.

Mantovani, A., Sica, A., Locati, M., 2005. Macrophage polarization comes of age. Immunity 23, 344-346.

Mass, E., Ballesteros, I., Farlik, M., Halbritter, F., Gunther, P., Crozet, L., JacomeGalarza, C.E., Handler, K., Klughammer, J., Kobayashi, Y., Gomez-Perdiguero, E., Schultze, J.L., Beyer, M., Bock, C., Geissmann, F., 2016. Specification of tissueresident macrophages during organogenesis. Science 353.

Meurens, F., Summerfield, A., Nauwynck, H., Saif, L., Gerdts, V., 2012. The pig: a model for human infectious diseases. Trends Microbiol. 20, 50-57.

Michel, M.C., Wieland, T., Tsujimoto, G., 2009. How reliable are G-protein-coupled receptor antibodies? Naunyn-Schmiedebergs Archives Pharmacol. 379, 385-388.

Murray, H.W., Szurosudol, A., Wellner, D., Oca, M.J., Granger, A.M., Libby, D.M., Rothermel, C.D., Rubin, B.Y., 1989. Role of Tryptophan degradation in respiratory burst-independent antimicrobial activity of gamma-interferon-stimulated human macrophages. Infect. Immun. 57, 845-849.

Murray, P.J., Allen, J.E., Biswas, S.K., Fisher, E.A., Gilroy, D.W., Goerdt, S., Gordon, S., Hamilton, J.A., Ivashkiv, L.B., Lawrence, T., Locati, M., Mantovani, A., Martinez, F.O., Mege, J.L., Mosser, D.M., Natoli, G., Saeij, J.P., Schultze, J.L.,
Shirey, K.A., Sica, A., Suttles, J., Udalova, I., van Ginderachter, J.A., Vogel, S.N., Wynn, T.A., 2014. Macrophage activation and polarization: nomenclature and experimental guidelines. Immunity 41, 14-20.

Muthu, K., Deng, J.P., Gamelli, R., Shankar, R., Jones, S.B., 2005. Adrenergic modulation of cytokine release in bone marrow progenitor-derived macrophage following polymicrobial sepsis. J. Neuroimmunol. 158, 50-57.

Muthu, K., He, L.-K., Szilagyi, A., Strotmon, P., Gamelli, R.L., Shankar, R., 2010. Betaadrenergic stimulation increases macrophage CD14 expression and E. coll phagocytosis through PKA signaling mechanisms. J. Leukoc. Biol. 88, 715-724.

Padro, C.J., Sanders, V.M., 2014. Neuroendocrine regulation of inflammation. Seminars Immunol. 26, 357-368.

Reynolds, G., Haniffa, M., 2015. Human and mouse mononuclear phagocyte networks: a tale of two species? Front. Immunol. 6.

Schroder, K., Irvine, K.M., Taylor, M.S., Bokil, N.J., Cao, K.A.L., Masterman, K.A., Labzin, L.I., Semple, C.A., Kapetanovic, R., Fairbairn, L., Akalin, A., Faulkner, G.J., Baillie J.K., Gongora, M., Daub, C.O., Kawaji, H., McLachlan, G.J., Goldman, N., Grimmond, S.M., Carninci, P., Suzuki, H., Hayashizaki, Y., Lenhard, B., Hume, D.A., Sweet, M.J., 2012. Conservation and divergence in Toll-like receptor 4-regulated gene expression in primary human versus mouse macrophages. Proceedings of the National Academy of Sciences of the United States of America 109, E944-E953.

Sigola, L.B., Zinyama, R.B., 2000. Adrenaline inhibits macrophage nitric oxide production through beta(1) and beta(2) adrenergic receptors. Immunology 100, 359-363.

Spengler, R.N., Allen, R.M., Remick, D.G., Strieter, R.M., Kunkel, S.L., 1990. Stimulation of alpha-adrenergic receptor augments the production of macrophage-derived tumor-necrosis-factor. J. Immunol. 145, 1430-1434.

Spiller, K.L., Wrona, E.A., Romero-Torres, S., Pallotta, I., Graney, P.L., Witherel, C.E., Panicker, L.M., Feldman, R.A., Urbanska, A.M., Santambrogio, L., VunjakNovakovic, G., Freytes, D.O., 2016. Differential gene expression in human, murine, and cell line-derived macrophages upon polarization. Exp. Cell Res. 347, $1-13$.

Sudan, B., Wacker, M.A., Wilson, M.E., Graff, J.W., 2015. A systematic approach to identify markers of distinctly activated human macrophages. Front. Immunol. 6.

Tanaka, S., Tsutsui, M., Kishida, T., Souma, S., Kuroda, J., Yoshida, T., 2010. Salbutamol inhibits lipopolysaccharide-induced inflammatory responses in rat peritoneal macrophages. J. Toxicol. Sci. 35, 327-334.

Thomas, A.C., Mattila, J.T., 2014. "Of mice and men": arginine metabolism in macrophages. Front. Immunol. 5.

Wirthgen, E., Tuchscherer, M., Otten, W., Domanska, G., Wollenhaupt, K., Tuchscherer, A., Kanitz, E., 2014. Activation of indoleamine 2,3-dioxygenase by LPS in a porcine model. Innate Immun. 20, 30-39.

Xiu, F., Stanojcic, M., Jeschke, M.G., 2013. Norepinephrine inhibits macrophage migration by decreasing CCR2 expression. PLoS One 8. 